\title{
Ibuprofen versus indomethacin treatment of patent ductus arteriosus: comparative effectiveness and complications
}

\author{
NM Chan *, CW Law, KF Kwan
}

This article was published on 30 January 2014 at www.hkmj.org.

\section{A B S T R A C T}

Objectives: To compare the effectiveness and complications of intravenous ibuprofen versus indomethacin treatment of patent ductus arteriosus in preterm infants.

Design: Retrospective case series.

Setting: A tertiary referral centre in Hong Kong.

Patients: A total of 95 infants who had received at least one course of indomethacin or ibuprofen for closure of patent ductus arteriosus from January 2008 to December 2011 were studied.

Main outcome measures: Following the total switch from indomethacin to ibuprofen in clinical use in April 2010, outcomes of infants receiving indomethacin and ibuprofen were compared. The primary outcomes including rates of failed medical closure and recourse to surgical ligation were compared. The secondary outcomes including rates of all-cause mortality, bronchopulmonary dysplasia, intestinal complications (necrotising enterocolitis, spontaneous intestinal perforation), change in urine output and serum creatinine, and progression of any intraventricular haemorrhage were also evaluated.

and 14 (33\%) in the ibuprofen group; for ibuprofen this yielded a relative risk of 1.06 (95\% confidence interval, $0.66-1.67 ; \mathrm{P}=0.852)$. The proportion of infants having surgical ligation was also similar. A higher rate of intestinal complications (necrotising enterocolitis or spontaneous intestinal perforation) was encountered in our ibuprofen group $(\mathrm{P}=0.043)$. No significant difference was observed in other secondary outcomes determined.

Conclusion: In our clinical practice, ibuprofen and indomethacin were shown to be equally effective for medical closure of patent ductus arteriosus in premature infants. With the higher rates of intestinal complications and similar effects on renal function in the ibuprofen group, we conclude that ibuprofen may not have fewer adverse effects than indomethacin.

\section{Hong Kong Med J 2014;20:205-12} DOI: 10.12809/hkmj134080

\section{NM Chan *, MRCPCH, FHKAM (Paediatrics) \\ CW Law, MB, BS, FHKAM (Paediatrics) \\ KF Kwan, FHKAM (Paediatrics)}

Department of Paediatrics, Queen Elizabeth Hospital, 30 Gascoigne Road, Kowloon, Hong Kong similar in the indomethacin and ibuprofen groups, with 16 (31\%) such infants in the indomethacin group

* Corresponding author: cnm312@ha.org.hk

- Ibuprofen was shown to be as effective as indomethacin for the medical closure of patent ductus arteriosus in
premature infants in clinical practice in Hong Kong.
Ibuprofen may not have fewer adverse effects than indomethacin, as it was associated with higher rates of
intestinal complications and similar effects on renal function.
Implications for clinical practice or policy
- Close monitoring for adverse effects is recommended in infants with patent ductus arteriosus treated with
either indomethacin or ibuprofen.

\section{Introduction}

Patent ductus arteriosus (PDA) is a common problem in preterm infants. Its occurrence is associated with prematurity and respiratory distress syndrome (RDS). ${ }^{1,2}$ A persistent left to right shunt in preterm neonates may be associated with neonatal morbidities, including bronchopulmonary dysplasia (BPD), intraventricular haemorrhage (IVH), and necrotising enterocolitis (NEC). ${ }^{3}$

Pharmacological closure of PDAs with indomethacin was first described in 1970s. ${ }^{4}$
Reported complications associated with the use of indomethacin included renal impairment, ${ }^{5}$ NEC, spontaneous intestinal perforation, ${ }^{6}$ and impaired cerebral blood flow. ${ }^{7}$ Ibuprofen, another cyclooxygenase inhibitor, has been investigated as an alternative to indomethacin for the same purpose. Published randomised controlled trials reported that ibuprofen was as efficacious as indomethacin for PDA closure, and some studies claimed that it had fewer adverse effects and gave rise to less renal impairment than indomethacin. ${ }^{8-11}$ 


\section{lbuprofen與 indomethacin於治療早產兒動脈導 管未閉的有效性和併發症的比較}

\section{陳藝敏、羅志偉、關國勳}

目的：比較indomethacin與ibuprofen應用於治療早產兒動脈導管未閉 的效果和併發症。

設計：回顧性病例系列研究。

安排：香港一所三級轉介中心。

患者：在2008年1月至2011年12月期間，於上述中心曾接受至少一次 療程的indomethacin與ibuprofen的95名患有早產兒動脈導管未閉的嬰 兒。

主要結果測量：隨着2010年4月在臨床治療早產兒動脈導管未閉上從 indomethacin到ibuprofen的轉變, 我們就這兩組嬰兒進行了比較。研 究的主要結果包括藥物治療成功率及需要手術結紮率。我們也就次要 結果, 包括全因死亡率、早產兒支氣管肺發育不良、腸道併發症（壞 死性腸炎或自發性腸穿孔）、尿量的變化、血清肌酐和腦室內出血率 進行了評估。

結果：Indomethacin和ibuprofen組之間在治療動脈導管未閉的失敗率 相似; 其中indomethacin組的 16 名嬰兒 (31\%) 和ibuprofen組的 14 名嬰兒 $(33 \%)$ 得出的相對危險度為 $1.06,95 \%$ 置信區間為0.66-1.67 $(\mathrm{P}=0.852)$ 。兩組嬰兒需要手術結紮的比例也相似。在我們的研究 中觀察到ibuprofen組的腸道併發症率（壞死性腸炎或自發性腸穿孔） 較高 $(\mathrm{P}=0.043)$ 。其他併發症的結果則無顯著性差異。

結論：本研究顯示ibuprofen和indomethacin在臨床實踐中治療早產兒 動脈導管未閉是同樣有效的。Ibuprofen引致的腸道併發症率較高, 對 腎功能的影響則與indomethacin相若。我們可以得出結論是ibuprofen 的不良反應可能不比indomethacin少。
The use of ibuprofen for closure of PDA has been increasing in clinical practice worldwide. In Hong Kong, indomethacin has been replaced by ibuprofen since 2010 due to interruption of the supply of indomethacin from the pharmaceutical company. Local data on its effectiveness and safety in clinical practice are very limited. A study comparing the use of ibuprofen versus indomethacin for this purpose could provide valuable data for clinicians regarding their use in clinical practice. At our unit, intravenous indomethacin had been used for treatment of PDA in preterm infants until April 2010. After that date, ibuprofen was used due to cessation of the supply of indomethacin from the pharmaceutical company supplying our hospital. We therefore set out to compare the two infant cohorts for treatment effectiveness and complications when used in our local setting.

\section{Methods}

\section{Patients and study design}

This retrospective study was conducted in the neonatal intensive care unit (NICU) of Queen Elizabeth Hospital, a tertiary referral centre in
Hong Kong with a level III neonatal intensive care service. The subjects in this study were all preterm infants admitted to the unit with their date of birth from 1 January 2008 to 31 December 2011 inclusive, and who had received at least one course of medical treatment for closure of a PDA with either indomethacin or ibuprofen. Due to the total switch from indomethacin to ibuprofen in clinical practice for this purpose in April 2010, we had information on two groups of infants - the indomethacin cohort (date of birth from 1 January 2008 to April 2010) and the ibuprofen cohort (date of birth from l April 2010 to 31 December 2011).

Preterm infants were defined as those who were born with less than 37 weeks of gestation. In our unit, preterm infants with clinical features suggestive of PDA, namely heart murmur, hypotension, hyperactive precordium, and increased ventilator settings were assessed by paediatric cardiologists. The diagnosis was then confirmed by echocardiography. Infants with a haemodynamically significant PDA were evaluated for medical closure with indomethacin/ibuprofen. Corresponding infants with features of heart failure, hypotension or who were ventilator-dependent were considered to have a haemodynamically significant PDA. Baseline assessments of these patients included platelet count, serum creatinine and electrolytes levels, urine output, and cranial ultrasound. Common contra-indications for the receipt of indomethacin/ ibuprofen included thrombocytopenia, bleeding tendency, progressing IVH, NEC, and impaired renal function. Indomethacin was given at $0.1 \mathrm{mg} / \mathrm{kg}$ intravenously at 24-hour intervals for six doses or $0.2 \mathrm{mg} / \mathrm{kg}$ intravenously every 24 hours for three doses. Ibuprofen was given at $10 \mathrm{mg} / \mathrm{kg}, 5 \mathrm{mg} / \mathrm{kg}$, and $5 \mathrm{mg} / \mathrm{kg}$ intravenously every 24 hours for a total of three doses. During the treatment courses, the infants were monitored for potential drug sideeffects. Enteral feeding was withheld during the treatment course. Ductal closure was defined as persistent disappearance of the heart murmur; some of whom also had echocardiographic confirmation. Infants who failed the first course of medical treatment were re-evaluated and received a second course. Infants who failed two courses of medical treatment were considered for surgical ligation of the PDA in another tertiary referral centre in Hong Kong. Apart from the switch from indomethacin to ibuprofen in April 2010, the clinical practice for PDA management remained unchanged.

\section{Data collection}

Eligible infants were identified by the Clinical Data Analysis and Reporting System, and their medical records were retrieved for data extraction. The neonatal demographic variables and baseline characteristics of both groups were collected and 
compared. The effectiveness of the drugs was primarily measured by (1) the failure rate of PDA closure after medical treatment, and (2) rate of recourse to surgical ligation. Secondary outcomes included all-cause mortality before discharge, BPD, adverse effects on renal function, gastro-intestinal complications (NEC and spontaneous intestinal perforation), and IVH. Occurrence of BPD was defined as (1) the use of supplement oxygen at 28 days of life or (2) the use of supplement oxygen at 36 weeks' postmenstrual age. Adverse effects on renal function were inferred by the magnitude of any serum creatinine and/or urine output change. Necrotising enterocolitis was diagnosed and classified according to modified Bell's staging. ${ }^{12}$ Intraventricular haemorrhage was classified according to the standard grading system. ${ }^{13}$

\section{Statistical analyses}

The two groups of infants receiving indomethacin or ibuprofen were compared using independent sample $t$ tests for continuous normally distributed data, while the Wilcoxon rank-sum test was used for continuous non-normal data. Chi squared and Fisher's exact tests were used as appropriate for categorical variables. The relative risks (RRs) of the outcome measures between the two groups were determined. The extent of change in urine output and serum creatinine level during the treatment course (within-subject effect) and the difference in change between the two groups (betweensubject effect) were analysed by repeated measures analysis of variance. Potential confounding factors for medical closure of the PDA, ${ }^{8}$ including gender, gestational age, RDS grading, PDA ductal diameter, and day of starting treatment were evaluated by logistic regression. Significant factors were then entered into a multivariate logistic regression model to determine adjusted odds ratios. In all the analyses, a P value of less than 0.05 was considered significant. The statistical analysis was performed using the Statistical Package for the Social Sciences (Windows version 16.0; SPSS Inc, Chicago [IL], US). The sample size estimation was based on the primary outcome measure: the difference in proportion of infants with medical closure between the two groups. The sample size calculation for a moderate effect size of 0.3 , power of $80 \%$, and an alpha of 0.05 indicated that around 40 subjects were needed in each group.

This study was approved by the Research Ethics Committee, Kowloon Central Cluster, Hospital Authority.

\section{Results}

\section{Baseline characteristics}

In all, 96 infants had medical treatment for closure of a PDA during the study period; 52 (55\%) received indomethacin only and 43 (45\%) received ibuprofen only. One infant, who received both indomethacin and ibuprofen during the transitional period, was excluded. There were no significant differences in the demographic variables and baseline characteristics of the two groups (Table 1), except for a higher proportion with severe IVH (grades 3 and 4) in the indomethacin group $(\mathrm{P}=0.01)$. There was no significant difference between these groups with respect to the number of infants receiving one or two courses of treatment (Table 1).

\section{Primary outcomes}

Regarding the effectiveness of treatment, 20 (38\%) of the infants in the indomethacin group and $18(42 \%)$ in the ibuprofen group failed medical treatment after the first course; the RR of failure for the latter compared to indomethacin was 1.09, the $95 \%$ confidence interval (CI) being 0.69 to 1.69 (Table 2). Considering all courses of treatment with indomethacin or ibuprofen, 16 (31\%) in the former group and 14 (33\%) in the latter group failed medical treatment. Eleven (21\%) infants in the indomethacin group and seven (16\%) in the ibuprofen group underwent surgical ligation of the PDA. For the primary outcome measure, both groups were very comparable.

Factors with a potential to affect medical closure of PDA were evaluated. Among them, gestational age, RDS, and age at the start of medical treatment were shown to be significantly related to the rate of surgical ligation of PDA, with borderline significance for age at start of treatment in the univariate analysis (Table 3). When the abovementioned significant factors were used in the multivariate analysis model, there was no significant difference between the two groups in terms of the rate of surgical ligation (adjusted odds ratio $=0.94$; 95\% CI, 0.27-3.26; $\mathrm{P}=0.923$ ).

\section{Secondary outcomes}

\section{Mortality}

Within the study cohort, two (4\%) infants in the indomethacin group and five (12\%) in the ibuprofen group died before being discharged, but this yielded no statistically significant difference in all-cause mortality.

\section{Respiratory outcomes}

The rates of BPD were also similar in both groups $(\mathrm{P}=0.615$ for use of supplement oxygen at 28 days and $\mathrm{P}=0.560$ at 36 weeks' postmenstrual age). The mean duration of invasive ventilation for the indomethacin group, however, was significantly longer than that for ibuprofen group (mean \pm standard deviation, $35 \pm 35$ vs $20 \pm 25$ days; $\mathrm{P}=0.045$ ), while the mean duration of oxygen dependency was similar $(\mathrm{P}=0.694$; Table 4$)$. 
TABLE I. Neonatal demographic variables and baseline characteristics*

\begin{tabular}{|c|c|c|c|}
\hline $\begin{array}{l}\text { Neonatal demographic variables and baseline } \\
\text { characteristics }\end{array}$ & $\begin{array}{l}\text { Indomethacin group } \\
(n=52)\end{array}$ & $\begin{array}{l}\text { Ibuprofen group } \\
(n=43)\end{array}$ & $\mathbf{P}$ value \\
\hline \multicolumn{4}{|l|}{ Demographic variable } \\
\hline Male & $28(54 \%)$ & $20(47 \%)$ & $0.477^{\mathrm{A}}$ \\
\hline Gestation (weeks) & $28.4 \pm 3.2$ & $28.8 \pm 2.9$ & $0.382^{c}$ \\
\hline Gestation category (weeks) & & & $0.958^{A}$ \\
\hline$\leq 25$ & $13(25 \%)$ & $9(21 \%)$ & \\
\hline $26-27$ & $14(27 \%)$ & $11(26 \%)$ & \\
\hline $28-29$ & $8(15 \%)$ & $6(14 \%)$ & \\
\hline $30-31$ & $9(17 \%)$ & $10(23 \%)$ & \\
\hline$\geq 32$ & $8(15 \%)$ & $7(16 \%)$ & \\
\hline Birth weight (g) & $1135 \pm 467$ & $1148 \pm 402$ & $0.562^{c}$ \\
\hline Birth weight category (g) & & & $0.804^{A}$ \\
\hline$\leq 750$ & $12(23 \%)$ & $7(16 \%)$ & \\
\hline $751-1000$ & $15(29 \%)$ & $12(28 \%)$ & \\
\hline $1001-1250$ & $9(17 \%)$ & $9(21 \%)$ & \\
\hline $1251-1500$ & $6(12 \%)$ & $8(19 \%)$ & \\
\hline$\geq 1501$ & $10(19 \%)$ & $7(16 \%)$ & \\
\hline Chinese ethnicity & 48 (92\%) & 40 (93\%) & $0.894^{\mathrm{A}}$ \\
\hline \multicolumn{4}{|l|}{ Baseline characteristic } \\
\hline Age of presentation (days) & $6.2 \pm 5.0$ & $4.6 \pm 2.2$ & $0.120^{c}$ \\
\hline PDA ductal diameter (mm) & $2.4 \pm 0.7$ & $2.5 \pm 0.9$ & $0.625^{\mathrm{B}}$ \\
\hline Age of start of 1st course (days) & $10.9 \pm 9.3$ & $7.7 \pm 4.0$ & $0.117^{c}$ \\
\hline RDS & $31(60 \%)$ & $33(77 \%)$ & $0.070^{\mathrm{A}}$ \\
\hline Inspired oxygen (\%)‡ & $26.9 \pm 13.2$ & $24.3 \pm 6.5$ & $0.259^{\mathrm{B}}$ \\
\hline Invasive ventilation $\ddagger$ & $27(52 \%)$ & $20(47 \%)$ & $0.413^{A}$ \\
\hline Platelet count $\left(\times 10^{9} / \mathrm{L}\right) \ddagger$ & $242 \pm 115$ & $220 \pm 97$ & $0.320^{\mathrm{B}}$ \\
\hline Serum creatinine $(\mu \mathrm{mol} / \mathrm{L}) \ddagger$ & $69.8 \pm 19.9$ & $71.6 \pm 22.9$ & $0.676^{\text {в }}$ \\
\hline Urine output $(\mathrm{mL} / \mathrm{kg} / \mathrm{h}) \ddagger$ & $4.6 \pm 1.5$ & $4.9 \pm 1.2$ & $0.487^{\mathrm{B}}$ \\
\hline IVH & $19(37 \%)$ & $12(28 \%)$ & $0.566^{A}$ \\
\hline Grade 3-4 IVH & $8(15 \%)$ & 0 & $0.01^{\mathrm{D}}$ \\
\hline \multicolumn{4}{|l|}{ No. of courses of treatment received } \\
\hline 1 & $34(65 \%)$ & $30(70 \%)$ & $0.28^{A}$ \\
\hline 2 & $15(29 \%)$ & $13(30 \%)$ & \\
\hline$\geq 3$ & $3(6 \%)$ & 0 & \\
\hline
\end{tabular}

Abbreviations: IVH = intraventricular haemorrhage; PDA = patent ductus arteriosus; RDS = respiratory distress syndrome

* Data are shown as No. (\%) of infants or mean \pm standard deviation

${ }^{+}{ }^{A}$ denotes Chi squared test, ${ }^{B}$ independent sample $t$ test, ${ }^{C}$ Wilcoxon rank-sum test, and ${ }^{\mathrm{D}}$ Fisher's exact test

$\ddagger$ These are the values prior to the start of treatment

\section{Gastro-intestinal effects}

Although not statistically significant, there was a higher rate of spontaneous intestinal perforation in the ibuprofen group ( $5 \%$ vs $0 \%, \mathrm{P}=0.202$ ), a higher rate of NEC ( $23 \%$ vs $12 \%, \mathrm{P}=0.129)$, and NEC stage 2 or above ( $7 \%$ vs $2 \%, \mathrm{P}=0.325$ ) in the ibuprofen group (Table 4). On the other hand, on considering infants with NEC or spontaneous intestinal perforation together, there was a significantly higher rate in the ibuprofen than indomethacin group $(\mathrm{P}=0.043)$, and the same was true for gastro-intestinal bleeding $(\mathrm{P}=0.024)$.

\section{Renal effects}

Mean baseline serum creatinine concentrations and urine outputs were similar in the two groups (Table 1). Renal function related to the first course of treatment with indomethacin or ibuprofen was 
TABLE 2. Effectiveness of treatment according to treatment group

\begin{tabular}{|c|c|c|c|c|}
\hline Treatment & $\begin{array}{l}\text { Indomethacin } \\
\text { group }\end{array}$ & $\begin{array}{l}\text { Ibuprofen } \\
\text { group }\end{array}$ & $\begin{array}{c}\text { Relative risk } \\
\quad(95 \% \mathrm{Cl})\end{array}$ & P value* \\
\hline \multicolumn{5}{|l|}{ 1st Course } \\
\hline Received 1 course & 52 & 43 & & \\
\hline Failed medical closure after 1 st course & $20(38 \%)$ & $18(42 \%)$ & $1.09(0.69-1.69)$ & $0.736^{\mathrm{A}}$ \\
\hline \multicolumn{5}{|l|}{ 2nd Course } \\
\hline Received 2 courses & 18 & 13 & & \\
\hline Failed medical closure after 2nd course & $15(83 \%)$ & $9(69 \%)$ & $0.66(0.29-1.50)$ & $0.413^{\mathrm{B}}$ \\
\hline \multicolumn{5}{|l|}{ Overall } \\
\hline Failed medically closure after all courses & $16(31 \%)$ & $14(33 \%)$ & $1.06(0.66-1.67)$ & $0.852^{\mathrm{A}}$ \\
\hline Surgical ligation of PDA & $11(21 \%)$ & $7(16 \%)$ & $0.87(0.57-1.33)$ & $0.546^{\mathrm{A}}$ \\
\hline
\end{tabular}

Abbreviations: $\mathrm{Cl}=$ confidence interval; $\mathrm{PDA}=$ patent ductus arteriosus

* A denotes Chi squared test and ${ }^{\mathrm{B}}$ Fisher's exact test

TABLE 3. Factors associated with recourse to surgical ligation for patent ductus arteriosus by univariate and multivariate analyses

\begin{tabular}{lcccc}
\hline Factor & Odds ratio (95\% Cl) & P value & Adjusted odds ratio (95\% Cl)† & P value \\
\hline Indomethacin/ibuprofen & $0.73(0.25-2.07)$ & 0.546 & $0.94(0.27-3.26)$ & 0.923 \\
Gestational age & $0.64(0.49-0.84)$ & 0.001 & $0.65(0.49-0.88)$ & 0.005 \\
Respiratory distress syndrome & $1.66(1.09-2.54)$ & 0.019 & $1.59(0.98-2.57)$ & 0.059 \\
Age of start of treatment (days) & $1.06(0.99-1.13)$ & 0.079 & $1.05(0.97-1.13)$ & 0.216 \\
\hline
\end{tabular}

Abbreviation: $\mathrm{Cl}=$ confidence interval

* Odds ratio in univariate analysis by simple logistic regression

† Adjusted odds ratio in multivariate analysis by multiple logistic regression

TABLE 4. Secondary outcomes according to treatment group*

\begin{tabular}{|c|c|c|c|}
\hline Secondary outcomes & $\begin{array}{l}\text { Indomethacin group } \\
(n=52)\end{array}$ & $\begin{array}{l}\text { Ibuprofen group } \\
(n=43)\end{array}$ & $P$ value \\
\hline All-cause mortality & $2(4 \%)$ & $5(12 \%)$ & $0.238^{c}$ \\
\hline \multicolumn{4}{|l|}{ Respiratory outcome } \\
\hline BPD at 28 days & $34(65 \%)$ & $24(56 \%)$ & $0.615^{\mathrm{A}}$ \\
\hline BPD at postmenstrual age of 36 weeks & $26(50 \%)$ & $17(40 \%)$ & $0.560^{\mathrm{A}}$ \\
\hline Mean duration of invasive ventilation (days) & $35 \pm 35$ & $20 \pm 25$ & $0.045^{\mathrm{B}}$ \\
\hline Mean duration of oxygen dependency (days) & $75 \pm 92$ & $61 \pm 60$ & $0.694^{\mathrm{B}}$ \\
\hline \multicolumn{4}{|l|}{ GI complication } \\
\hline Gl bleeding & $4(8 \%)$ & $11(26 \%)$ & $0.024^{c}$ \\
\hline NEC & $6(12 \%)$ & $10(23 \%)$ & $0.129^{A}$ \\
\hline NEC (stage 2 or above) & $1(2 \%)$ & $3(7 \%)$ & $0.325^{c}$ \\
\hline Spontaneous intestinal perforation & 0 & $2(5 \%)$ & $0.202^{c}$ \\
\hline GI conditions requiring operation & $1(2 \%)$ & $4(9 \%)$ & $0.172^{c}$ \\
\hline NEC or spontaneous intestinal perforation & $6(12 \%)$ & $12(28 \%)$ & $0.043^{A}$ \\
\hline IVH progression & $3(6 \%)$ & $1(2 \%)$ & $0.644^{\mathrm{C}}$ \\
\hline
\end{tabular}

Abbreviations: BPD = bronchopulmonary dysplasia; $\mathrm{Gl}$ = gastro-intestinal; IVH = intraventricular haemorrhage; $\mathrm{NEC}=$ necrotising enterocolitis

* Data are shown as No. (\%) of infants or mean \pm standard deviation

$\dagger^{\mathrm{A}}$ denotes Chi squared test, ${ }^{\mathrm{B}}$ independent sample $t$ test, and ${ }^{\mathrm{C}}$ Fisher's exact test 
also studied. For within-subject effects, there were significant decreases in urine output $(\mathrm{P}<0.001)$ and increases in serum creatinine level $(\mathrm{P}=0.004)$ over time during treatment. For between-subjects effect, there was no significant difference in the changes of serum creatinine $(\mathrm{P}=0.829)$ and urine output $(\mathrm{P}=0.498)$ in the two groups, indicating that both drugs had a significant and comparable effect on renal function as measured by serum creatinine level and urine output (Fig).

\section{Intraventricular haemorrhage}

A larger proportion of infants in the indomethacin group had severe IVH at baseline. However, in both groups the rates of progression of IVH after treatment were similar $(\mathrm{P}=0.644)$.

\section{Discussion}

Our study compared the effectiveness and sideeffects of intravenous indomethacin versus ibuprofen in treating PDA in preterm infants in two cohorts of Hong Kong patients. Our results demonstrate no significant difference in baseline characteristics between the two groups, thus justifying comparison of the cohorts. The two drugs appear to have similar effectiveness as measured by the rate of medical closure and surgical ligation rate of PDAs; such finding was also consistent with previous randomised controlled trials ${ }^{8-11}$ and cohort studies. ${ }^{14,15}$ Even after potential confounding factors (discussed in the previous literature ${ }^{8}$ ) were controlled, the effectiveness of the two drugs did not differ significantly.

A higher all-cause mortality rate was observed in the ibuprofen group, although this did not reach statistical significance. The mortality case analysis was limited by the small number of deaths in each group; the power calculated was only $25 \%$. Similar findings were reported by Katakam et al. ${ }^{15}$ When considering the individual cases, we observed that two infants in the ibuprofen group might have died of drug-related complications, namely spontaneous intestinal perforation and acute renal failure. Although one should not be biased by individual cases, these deaths illustrate the potential for fatal complications related to this drug.

We found no significant difference in the risk of $\mathrm{BPD}$ in the two groups; such result was consistent with that of a recent Cochrane review. ${ }^{16}$ By contrast another review by Jones et $\mathrm{al}^{17}$ concluded that intravenous ibuprofen may be associated with an increased risk of BPD when compared with intravenous indomethacin. These inconsistencies may be related to the definitions of BPD that were used. Our study considered BPD using the two most commonly used definitions (supplement oxygen use at 28 days and at 36 weeks' postmenstrual age, separately). Notably, similar rates of BPD were observed in the two groups for both definitions. By contrast, the duration of invasive ventilation was significantly longer in the indomethacin group. In this respect, a possible explanation and limitation of our study was that there may have been a gradual change in ventilation strategy over time, with a trend towards non-invasive ventilation. ${ }^{18}$

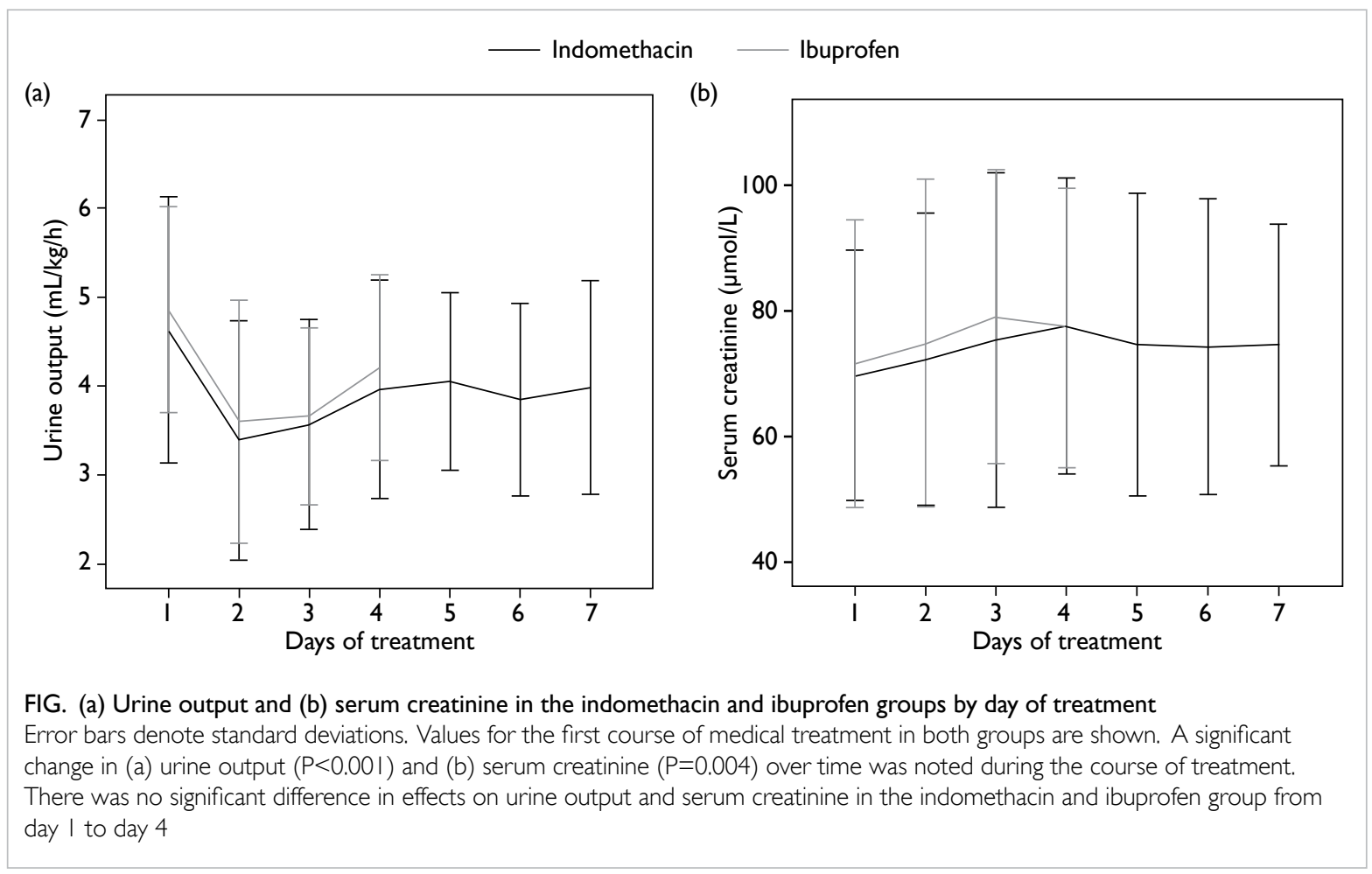


Regarding evaluation of possible gastrointestinal complications, two conditions (NEC and spontaneous intestinal perforation) have been described. Both are believed to be associated with impaired mesenteric blood flow due to a PDA as well as the use of cyclo-oxygenase inhibitors, though some recent studies have reported on the difference in clinical presentations and histological findings between these two entities. ${ }^{19,20}$ We observed a statistically higher rate of intestinal complications (NEC or spontaneous intestinal perforation) in the ibuprofen group $(\mathrm{P}=0.043)$. In contrast, the latest Cochrane review ${ }^{16}$ reported less NEC in the ibuprofen group ( $\mathrm{RR}=0.68$; 95\% CI, 0.47-0.99). The management practice of preterm infants in our unit, including the feeding regimen, remained unchanged during the study period. Thus, this particular inconsistency could not be attributed to any known factors. Kushnir and Pinheiro ${ }^{14}$ studied 350 infants and also reported a higher rate of NEC in ibuprofen than indomethacin users ( $8 \%$ vs $4 \% ; \mathrm{P}=0.08)$. Rao et $\mathrm{al}^{19}$ studied 102 infants with PDA treated with ibuprofen, and reported a $9 \%$ rate of spontaneous intestinal perforation and $6 \%$ rate of NEC; such figures were comparable to those in our ibuprofen cohort. These findings suggest that compared with preterm infants treated with indomethacin, intestinal complications appear to be more common in those receiving ibuprofen.

We found that indomethacin and ibuprofen had a similar effect on renal function, though previous literature ${ }^{8,9,15-17}$ indicated that ibuprofen had less effect on renal blood flow and renal function. This inconsistency could be related to differences in how measurement of renal function was carried out. We evaluated the change in serum creatinine and urine output during the course of treatment. The change in these parameters, rather than the absolute values, might be better parameters to assess due to variations in serum creatinine with gestational age and the age of the infants. ${ }^{21}$ Another problem was the timing of measurements. Akima et $\mathrm{al}^{22}$ evaluated the renal effects of indomethacin and reported a significant increase in serum creatinine level on day 2 and day 7 of treatment when compared with the controls. Due to differences in the duration of treatment courses with the two drugs, the best time to carry out comparisons remains unclear. Moreover, as observed in one of our infants given ibuprofen who also developed acute renal failure 2 days after the completion of second course, there could be delayed and cumulative effects on renal function with repeat treatment courses. This was also shown by Kushnir and Pinheiro, ${ }^{14}$ whereby indomethacin had a more prominent effect on renal function during the first course while both drugs led to equal adversity at the second and third courses. However, the retrospective design of our study was a limitation as some data (especially on day 4 and later) in the ibuprofen group were influenced by the course lasting only 3 days, whilst data on the repeat courses of treatment were less complete. Hence, our study evaluated the first 4 days of the first course of treatment, and evaluation of repeat courses was excluded. With regard to the significant renal effects of ibuprofen and indomethacin noted in our study, we recommend close monitoring of renal function when either drug is used. Special cautions may be necessary for repeat courses of treatment.

Till now, published studies on the efficacy and safety of ibuprofen versus indomethacin were mainly randomised trials. The subjects in randomised trials were selected using inclusion and exclusion criteria that may be less representative of the whole spectrum of infants in clinical practice. For instance, randomised trials by Van Overmeire et $\mathrm{al}^{8}$ and Lago et $\mathrm{al}^{9}$ only studied infants with PDA treatment given in the first 2 to 4 days of life and RDS was an inclusion criterion. Our study included all infants that were treated within the study period, maximising the representativeness of the sample. Being a retrospective study to investigate the effectiveness and complications related to drug therapy in a clinical setting, the allocation of treatment was not randomised or blinded. However, selection bias was minimised as the drug treatment each infant received was only determined by the month and year they were admitted to the neonatal unit. On the other hand, being a study from two contiguous time periods, there may have been minor modifications of clinical practice despite that both infant cohorts being managed by the same group of clinicians and there being no change in departmental guidelines for management of PDAs.

Our study shared the limitations of most previous studies. Our sample size estimation was based on the primary outcome (the rate of successful medical closure). As the sample size was limited by the number of eligible infants within the study period, the effect size adopted in the sample size estimation was 0.3 , which was moderate compared to other similar studies. Moreover, with respect to adverse outcome evaluation, infant numbers with positive findings were small, which affected the precision of our analyses. Another limitation was that two regimens of the indomethacin were used in our hospital: $0.1 \mathrm{mg} / \mathrm{kg} / \mathrm{dose}$ every 24 hours for six doses (prolonged course) and $0.2 \mathrm{mg} / \mathrm{kg} / \mathrm{dose}$ every 24 hours for three doses (short course). Fortunately, this heterogeneity within the group was small, as the majority of infants received the prolonged course (46 out of 52). Moreover, previous studies comparing these two regimens showed that their efficacy did not differ significantly. ${ }^{23,24}$ As for the generalisability of our study, variations in management of symptomatic PDA do exist between centres, ${ }^{25,26}$ and there is no consensus approach. Our 
practice, for trial of a second course of indomethacin or ibuprofen before considering surgical ligation, entailed intense monitoring for adverse effects, which was consistent with common practice. ${ }^{23}$ Thus, our study could provide useful information for other NICUs to consider for the management of PDA in preterm infants.

\section{Conclusion}

In clinical practice, intravenous ibuprofen is as effective as indomethacin for the medical closure of PDAs in premature infants. However, owing to the higher rates of intestinal complications after ibuprofen therapy, we conclude that it may not have fewer adverse effects than indomethacin. Neonatologists are therefore advised to cautiously monitor for possible side-effects in preterm infants receiving either indomethacin or ibuprofen for the treatment of PDAs.

\section{Declaration}

No conflicts of interests were declared by authors.

\section{References}

1. Kitterman JA, Edmunds LH Jr, Gregory GA, Heymann MA, Tooley WH, Rudolph AM. Patent ductus arteriosus in premature infants - incidence, relation to pulmonary disease and management. N Engl J Med 1972;287:473-7.

2. Thibeault DW, Emmanouilides GC, Nelson RJ, Lachman RS, Oh W. Patent ductus arteriosus complicating the respiratory distress syndrome in preterm infants. J Pediatr 1975;86:120-6.

3. Clyman RI, Chorne N. Patent ductus arteriosus: evidence for and against treatment. J Pediatr 2007;150:216-9.

4. Friedman WF, Hirschklau MJ, Printz MP, Pitlick PT, Kirkpartrick SE. Pharmacologic closure of patent ductus arteriosus in the premature infant. N Engl J Med 1976;295:526-9.

5. Seyberth HW, Rascher W, Hackenthal R, Wille L. Effect of prolonged indomethacin therapy on renal function and selected vasoactive hormones in very low birth weight infants with symptomatic patent ductus arteriosus. I Pediatr 1983;103:979-84.

6. Fujii AM, Brown E, Mirochnick M, O’Brien S, Kaufman G. Neonatal necrotizing enterocolitis with intestinal perforation in extremely premature infants receiving early indomethacin treatment for patent ductus arteriosus. J Perinatol 2002;22:535-40.

7. Edwards AD, Wyatt JS, Richardson $\mathrm{C}$, et al. Effects of indomethacin on cerebral haemodynamics in very preterm infants. Lancet 1990;335:1491-5.

8. Van Overmeire B, Smets K, Lecoutere D, et al. A comparison of ibuprofen and indomethacin for closure of patent ductus arteriosus. N Engl J Med 2000;343:674-81.

9. Lago P, Bettiol T, Salvadori S, et al. Safety and efficacy of ibuprofen versus indomethacin in preterm infants treated for patent ductus arteriosus: a randomised controlled trial. Eur J Pediatr 2002;161:202-7.

10. Mosca F, Bray M, Lattanzio M, Fumagalli M, Tosetto C.
Comparative evaluation of the effects of indomethacin and ibuprofen on cerebral perfusion and oxygenation in preterm infants with patent ductus arteriosus. J Pediatr 1997;131:549-54.

11. Su BH, Lin HC, Chiu HY, Hsieh HY, Chen HH, Tsai YC. Comparison of ibuprofen and indomethacin for earlytargeted treatment of patent ductus arteriosus in extremely premature infants: a randomized controlled trial. Arch Dis Child Fetal Neonatal Ed 2008;93:F94-9.

12. Kliegman RM, Walsh MC. Neonatal necrotizing enterocolitis: pathogenesis, classification, and spectrum of illness. Curr Probl Pediatr 1987;17:213-88.

13. Papile LA, Burstein J, Burstein R, Koffler H. Incidence and evolution of subependymal and intraventricular hemorrhage: a study of infants with birth weights less than 1,500 gm. J Pediatr 1978;92:529-34.

14. Kushnir A, Pinheiro JM. Comparison of renal effects of ibuprofen versus indomethacin during treatment of patent ductus arteriosus in contiguous historical cohorts. BMC Clin Pharmacol 2011;11:8.

15. Katakam LI, Cotton CM, Goldberg RN, Dang CN, Smith PB. Safety and effectiveness of indomethacin versus ibuprofen for treatment of the patent ductus arteriosus. Am J Perinatol 2010;27:425-9.

16. Ohlsson A, Walia R, Shah SS. Ibuprofen for the treatment of patent ductus arteriosus in preterm and/ or low birth weight infants. Cochrane Database Syst Rev 2010;(4):CD003481.

17. Jones LJ, Craven PD, Attia J, Thakkinstian A, Wright I. Network meta-analysis of indomethacin versus ibuprofen versus placebo for PDA in preterm infants. Arch Dis Child Fetal Neonatal Ed 2011;96:F45-52.

18. Ramanathan R, Sardesai S. Lung protective ventilatory strategies in very low birth weight infants. J Perinatol 2008;28 Suppl 1:S41-6.

19. Rao R, Bryowsky K, Mao J, Bunton D, McPherson C, Mathur A. Gastrointestinal complications associated with ibuprofen therapy for patent ductus arteriosus. J Perinatol 2011;31:465-70.

20. Attridge JT, Clark R, Walker MW, Gordon PV. New insights into spontaneous intestinal perforation using a national data set: (2) two populations of patients with perforations. J Perinatol 2006;26:185-8.

21. Bueva A, Guignard JP. Renal function in preterm neonates. Pediatr Res 1994;36:572-7.

22. Akima S, Kent A, Reynolds GJ, Gallagher M, Falk MC. Indomethacin and renal impairment in neonates. Pediatr Nephrol 2004;19:490-3.

23. Tammela O, Ojala $R$, Iivainen $T$, et al. Short versus prolonged indomethacin therapy for patent ductus arteriosus in preterm infants. J Pediatr 1999;134:552-7.

24. Siu KL, Wan KM, Law CW, Lee WH. Indomethacin regimes for patent ductus arteriosus in premature newborn. HK J Paediatr (New Series) 1997;2:180-1.

25. Amin SB, Handley C, Carter-Pokras O. Indomethacin use for the management of patent ductus arteriosus in preterms: a web-based survey of practice attitudes among neonatal fellowship program directors in the United States. Pediatr Cardiol 2007;28:193-200.

26. Brissaud O, Guichoux J. Patent ductus arteriosus in the preterm infant: a survey of clinical practices in French neonatal intensive care units. Pediatr Cardiol 2011;32:60714 